Stephan A. Bolliger

Michael J. Thali

Steffen Ross

Ursula Buck

Silvio Naether

Peter Vock

\section{Virtual autopsy using imaging: bridging radiologic and forensic sciences. A review of the Virtopsy and similar projects}

Received: 26 March 2007

Revised: 25 June 2007

Accepted: 16 July 2007

Published online: 18 August 2007

(C) Springer-Verlag 2007
S. A. Bolliger $(\bowtie) \cdot$ M. J. Thali •

S. Ross - U. Buck - S. Naether

Centre for Forensic Imaging and

Virtopsy, Institute of Forensic

Medicine, University of Bern,

Buehlstrasse 20,

3012 Bern, Switzerland

e-mail: stephan.bolliger@irm.unibe.ch

Tel.: +41-31-6318411

Fax: +41-31-6313833

P. Vock

Department for Diagnostic Radiology, Inselspital, University of Bern,

3010 Bern, Switzerland

\begin{abstract}
The transdisciplinary research project Virtopsy is dedicated to implementing modern imaging techniques into forensic medicine and pathology in order to augment current examination techniques or even to offer alternative methods. Our project relies on three pillars: threedimensional (3D) surface scanning for the documentation of body surfaces, and both multislice computed tomography (MSCT) and magnetic resonance imaging (MRI) to visualise the internal body. Three-dimensional surface scanning has delivered remarkable results in the past in the $3 \mathrm{D}$ documentation of patterned injuries and of objects of forensic interest as well as whole crime scenes. Imaging of the interior of corpses is performed using MSCT and/or MRI. MRI, in
\end{abstract}

addition, is also well suited to the examination of surviving victims of assault, especially choking, and helps visualise internal injuries not seen at external examination of the victim. Apart from the accuracy and threedimensionality that conventional documentations lack, these techniques allow for the re-examination of the corpse and the crime scene even decades later, after burial of the corpse and liberation of the crime scene. We believe that this virtual, non-invasive or minimally invasive approach will improve forensic medicine in the near future.

Keywords Forensic imaging . Virtopsy · Computed tomography · Magnetic resonance imaging . Surface scanning

\section{Introduction}

Forensic science has experienced revolutionary changes in different fields, such as genetics, crime scene investigation methods and toxicology. Forensic pathology, by contrast, still utilises the time-old, evidence-based methods introduced centuries ago; namely, the dissection of a corpse, and an oral description and written documentation of the findings obtained [1]; this has been augmented in the past decades by photography.

With the advance of medical technologies such as computed tomography (CT) introduced by Hounsfield and Cormack in the early 1970 s, new possibilities became available for forensic pathologists. A first CT scan was performed on a victim of a gunshot injury to the head as early as 1977 [2] and authors such as Brogdon [3] and
Vogel [4] have mentioned the usefulness of radiology in forensic medicine.

Although conventional X-rays have found their way into daily forensic practice, newer, clinically established methods, such as CT and magnetic resonance imaging (MRI), seem to lag behind in their forensic implementation.

This conservative attitude towards new technologies is surprising in a field in which prosecutors and defence lawyers are, depending on the case circumstances, often eager to test novel methods.

Regardless of these obstacles, many different institutions have implemented CT in post-mortem forensic investigations. For instance, a group from the Office of the Armed Forces Medical Examiner (Armed Forces Institute of Pathology, Washington, D.C., and Dover, Del.), which performs CT scans on military personnel killed in combat 
on a routine basis evaluated the usefulness of CT in the assessment of high velocity gunshot victims with promising results [5]. Groups from the universities of Copenhagen (Denmark) and Linkoping (Sweden) have started CT scanning on corpses on a broad scale [6,7], here again with promising results. According to personal communication, every corpse delivered to the Victorian Institute of Pathology (Sydney, Australia) undergoes a CT scan prior to autopsy. Also dedicated to this novel approach, the Society for Autopsy Imaging in Japan was founded in 2003 [8]. CT scanning has also been introduced into forensic anthropology. A French group actually obtained superior results when assessing the case of a charred body with respect to anthropological aspects compared with traditional methods [9].

In Switzerland, this revolution in forensic science started off in the mid-nineties, when the Institute of Forensic Medicine of the University of Bern started a project with the Scientific Service of the City Police of Zuerich. The aim was to document body and object surfaces in a threedimensional (3D) fashion. A few years later, the Institute of Forensic Medicine again started a joint research project, this time with the Institutes of Diagnostic Radiology and Neuroradiology of the University of Bern. This project had the ambitious aim of detecting forensic findings of corpses using multislice CT (MSCT) and MRI, and of comparing these results with autopsy findings.

This was the beginning of the Virtopsy project. Later on, further methods and tools were added in addition to MSCT and MRI, so that now the project implements an ever expanding variety of imaging methods.

The main tools already implemented in daily forensic practice are:

- 3D photogrammetry-based optical surface scanning

- MSCT

- MRI.

These different tools are discussed separately below.

\section{D photogrammetry-based optical scanning}

Photography with a reference ruler is the standard documentation method of injuries and injury inflicting objects in forensic medicine. The three-dimensionality of these structures is reduced to a $2 \mathrm{D}$ level by classic photography.

However, using the TRITOP/ATOS III system (GOM, Braunschweig, Germany), such surfaces can be documented in a $3 \mathrm{D}$ fashion.

This system consists basically of one central projection unit and two digital cameras mounted beside the projector. A fringe pattern is projected onto the surface of the object, which is recorded by the two cameras. Based on the principle of triangulation, 3D coordinates are calculated by the scanning software ATOS. Thus, a 3D surface can be recalculated.

Digital photography of the surface of the object of interest from different angles with reference markers can, using the TRITOP software, add colour information to the otherwise black-and white 3D surface.

This method is applicable for the true-colour surface documentation of corpses, of objects suspected of having caused an injury, of vehicles and of entire crime scenes.

These three-dimensional models can be compared, thus allowing for the identification of an object or structure suspected of having caused the injury [10-12].

Another example of the use of 3D surface data is its application in complex traffic accidents. A comparison of the injuries sustained by the victim and the corresponding structures on the vehicle (Fig. 1) helps reconstruct the course of an accident [13].

\section{MSCT}

This is indeed the most frequently used tool in our project. At present, over 200 corpses have undergone MSCT scanning prior to autopsy; currently, we use a six-detectorrow scanner (Emotion 6, Siemens Medical Systems, Erlangen, Germany). Scans are usually performed with a $1.25-\mathrm{mm}$ section thickness and a reconstruction increment of $0.7 \mathrm{~mm}$. Regions of special interest, such as delicate fractures or the dentition, are scanned with thinner slice thicknesses and reconstruction increments $(0.63 \mathrm{~mm}$ and $0.5 \mathrm{~mm}$, respectively).

The CT images are read by board-certified radiologists and compared with autopsy findings acquired by boardcertified forensic pathologists $[14,15]$.

The CT examination has proven to be an invaluable tool in three areas of forensic pathology; namely, in the detection and demonstration of fractures, the detection of foreign bodies and the detection of gas.

Detection of osseous lesions

Osseous injuries obviously play an important role in forensic pathology, be it in the form of fractures, of cuts, or of gunshot injuries. Cuts and fractures - and in the case of whole body scans, even the fracture distribution and 3D pattern of dislocation - can be visualised easily and presented in a non-bloody form to medical laymen and facilitate their understanding of the case (Figs. 2, 3). Furthermore, small fractures at regions of the body which are difficult to access and which may be overlooked at autopsy can be detected easily. Another advantage is that certain areas of the body not routinely dissected, such as the face, can be examined with regard to fractures in a nondestructive fashion (Fig. 4), thus sparing the next of kin more psychological trauma. 

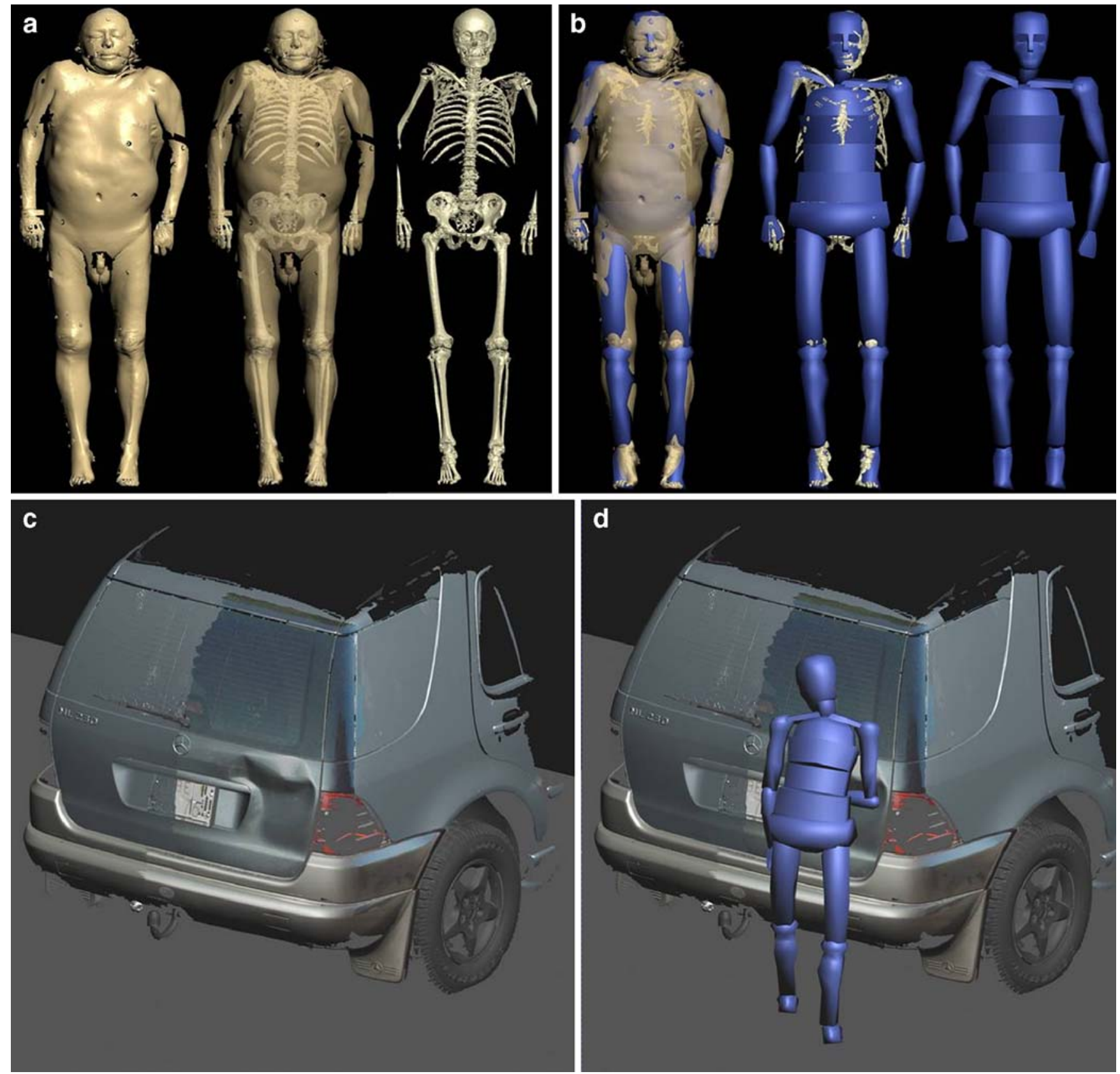

Fig. 1a-d Three-dimensional surface scanning of a traffic accident. A car allegedly ran into a pedestrian whilst driving backwards. The man was knocked down, run over and eventually succumbed to fat embolism. The body surface was scanned and fused with the CT data of the skeleton (a). Thanks to the scaled proportions obtained in

\section{Detection of foreign bodies}

$\mathrm{X}$-rays are routinely employed in order to detect foreign bodies in corpses, be it projectiles [16], knife blades [17] or medical implants, etc. (Fig. 5). MSCT has the additional advantage that it can locate exactly these objects and demonstrate their topographic neighbourhood within the the step shown in a, a correctly proportioned model of the corpse is obtained (b). After scanning the vehicle in question (c), the body model obtained in the step described in $\mathbf{b}$ was matched to the damages of the model of the car seen in $\mathbf{c}(\mathbf{d})$

body in a 3D manner, thus facilitating the extraction at autopsy enormously. For identification, 3D data can be transformed to $2 \mathrm{D}$ projections or tomographic views; one typical application is the creation of 2D panoramic dental images corresponding to ante-mortem radiographic documents [18]. Another advantage of MSCT over conventional $\mathrm{X}$-rays is that MSCT can measure the radiological density 


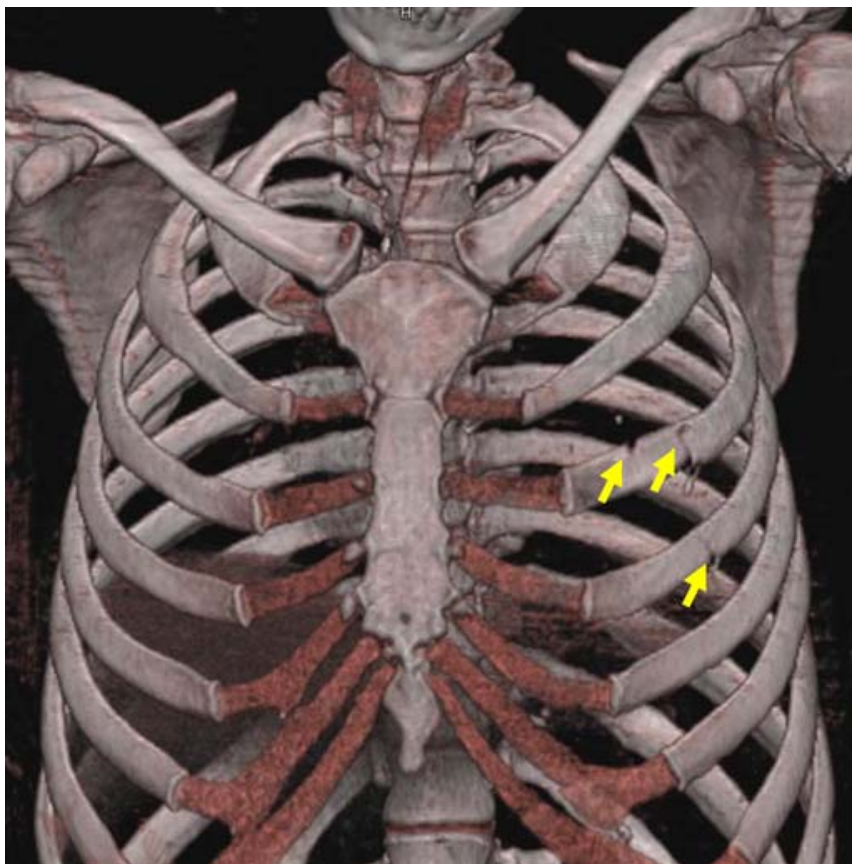

Fig. 2 MSCT, 3D bone reconstruction of the chest of a young woman stabbed 13 times into the left side of her chest by her flatmate. Note the injuries to the ribs (arrows) due to the stabs. Although the diagnosis of such lesions is performed on 2D images, such 3D reconstructions help demonstrate findings to medical laymen, for instance at court

of the foreign body. In CT, this density is expressed in Hounsfield Units (HU). Metal objects, for example, reach densities of over 1,000 HU. Composite dental fillings have densities of 4,500-17,000 HU, temporary fillings of 6,000$85,000 \mathrm{HU}$, and amalgam and gold of $>30,710 \mathrm{HU}$. If one knows the different densities, one can therefore assess the nature of these prior to autopsy. In mass catastrophes, this might facilitate enormously the identification process. Likewise, it may be of importance to differentiate between metal objects (for example projectiles) and bone fragments before opening the body (Fig. 6).

\section{Detection of gas}

Pneumothorax and gas embolism are difficult to detect at autopsy. For the former, one has to create a pleural window and to assess whether the lung collapses in the pleural cavity upon puncturing the intercostal space. Diagnosing gas embolism is even more difficult: the heart is punctured whilst submerged in water in the pericardial sack. If bubbles rise to the water surface, this confirms the presence of gas in the cardiac chamber. In both locations, autopsy has a great disadvantage: it cannot determine the amount of gas. Furthermore, the mere presence of gas in a cardiac chamber does not necessarily imply that this gas was embolised.
MSCT can overcome most of these difficulties easily. Sectional images depict the presence of gas immediately (Fig. 7), whilst 3D reconstructions display the gas distribution in the blood vessels (Fig. 8) and the cardiac chambers, and even the precise amount may be determined [19]. It is a basic advantage of imaging that, as the decomposing body is sealed in at least one air-tight body bag, the smell of putrefaction is kept at a minimum during the examination.

\section{MRI}

In our project, MRI is routinely performed on a 1.5 -Tesla system (Signa v5.8; GE Medical Systems, Milwaukee, Wis.) at the Institute of Diagnostic Radiology of the University of Bern. At present, a 3-Tesla system and a 1.5-Tesla total imaging matrix system are also being evaluated.

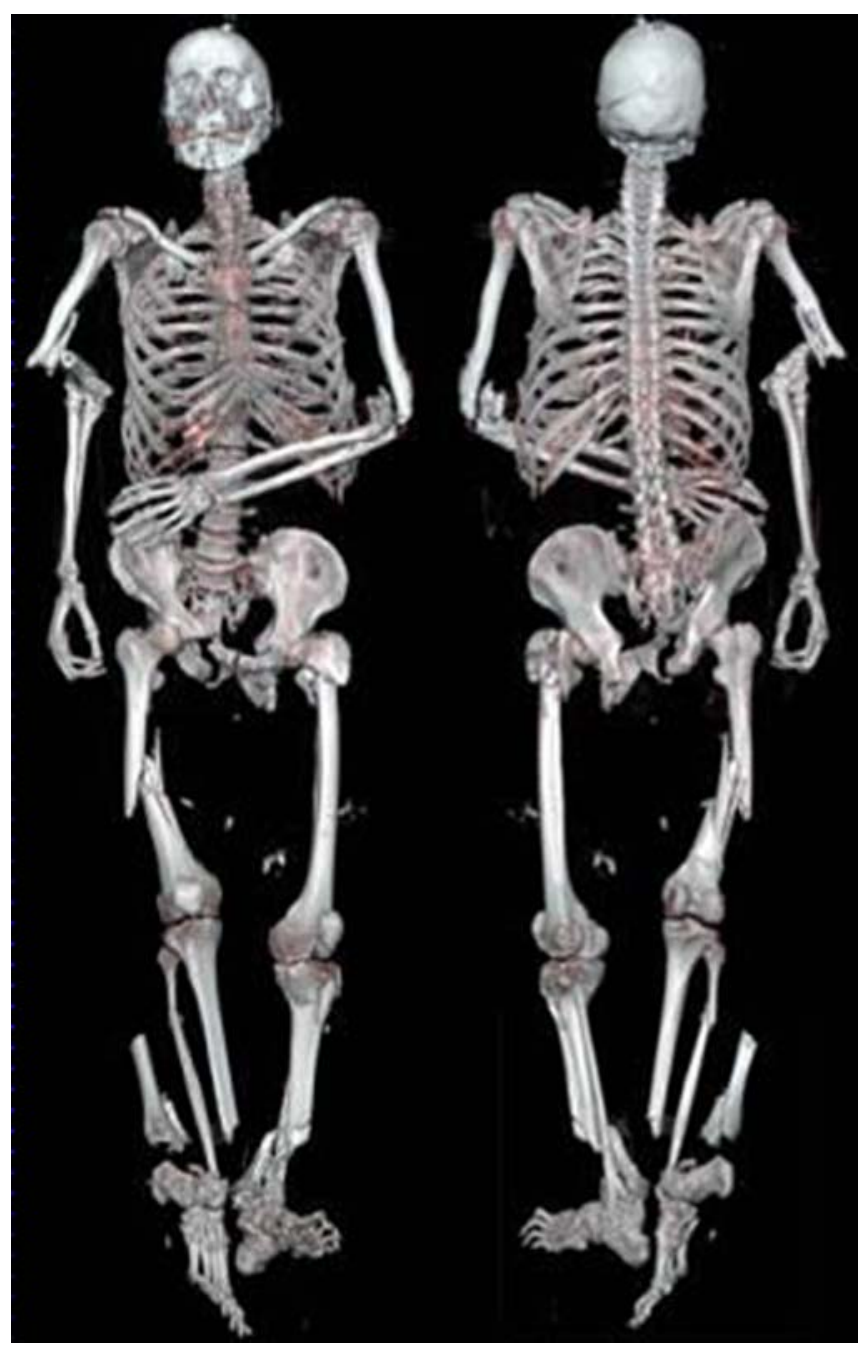

Fig. 3 MSCT, 3D reconstruction of the entire skeleton of a victim of a fall from great height, demonstrating multiple fractures, including the type and degree of dislocation 


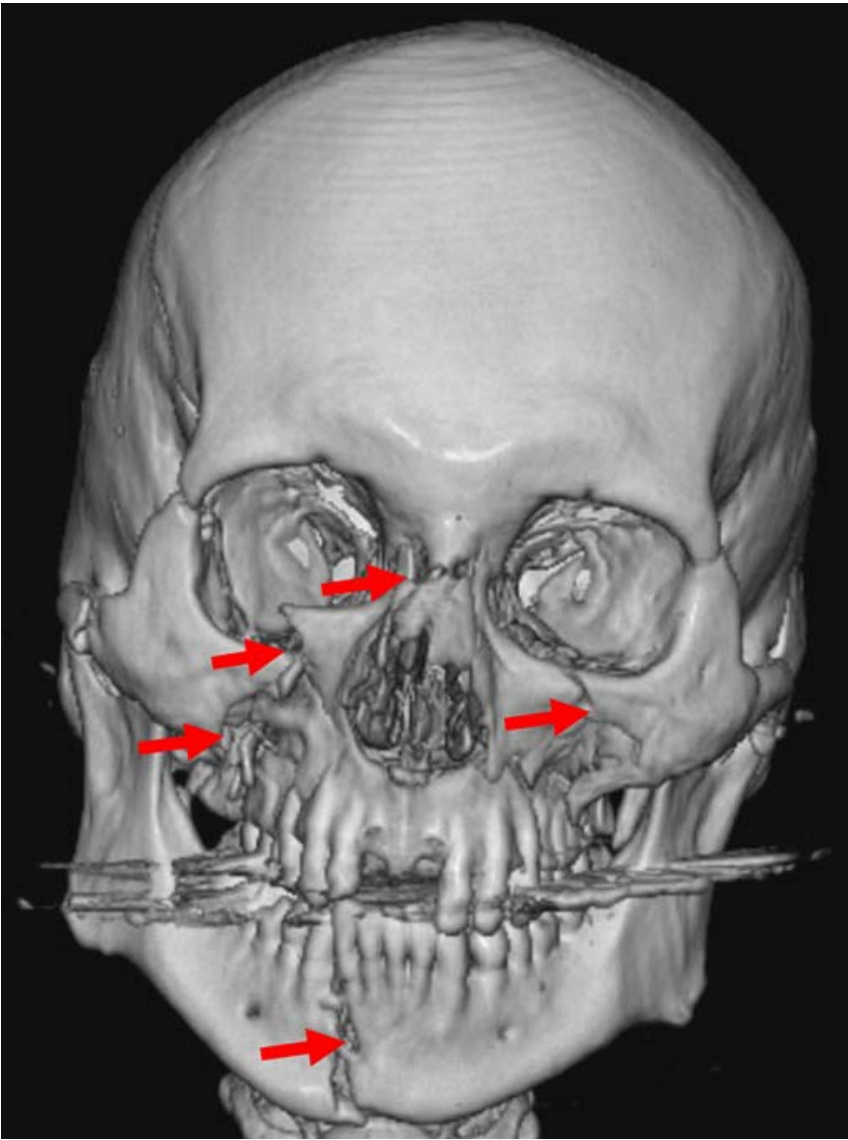

Fig. 4 MSCT, 3D reconstruction of the skull of a traffic accident victim. The viscerocranial fractures are clearly depicted (arrows). Autoptic demonstration of these fractures would have necessitated an extensive and destructive dissection of the face

MRI relies on the relaxation properties of excited mobile hydrogen nuclei in water, tissues and fat. Therefore, soft tissues, which obviously possess large quantities of hydrogen, are depicted excellently (Fig. 9).

The pathology of subcutaneous fatty tissue, one of the predilection sites in blunt trauma [20], is clearly seen in MRI, as are the inner organs [14, 21-29]. Fatal haemorrhage can be detected both by MRI and by CT [30].

Since it does not use ionizing radiation and since it is well suited for the depiction of soft tissue pathology, MRI is also regularly utilised within the project in the assessment of surviving victims of blunt trauma, especially of manual strangulation [31]. The problem in such cases is that the superficial findings may be innocuous, but the underlying soft tissues - especially around the reflectogenic structures of the throat - may be severely traumatised (Fig. 10), thus leading to a potentially life-threatening situation.

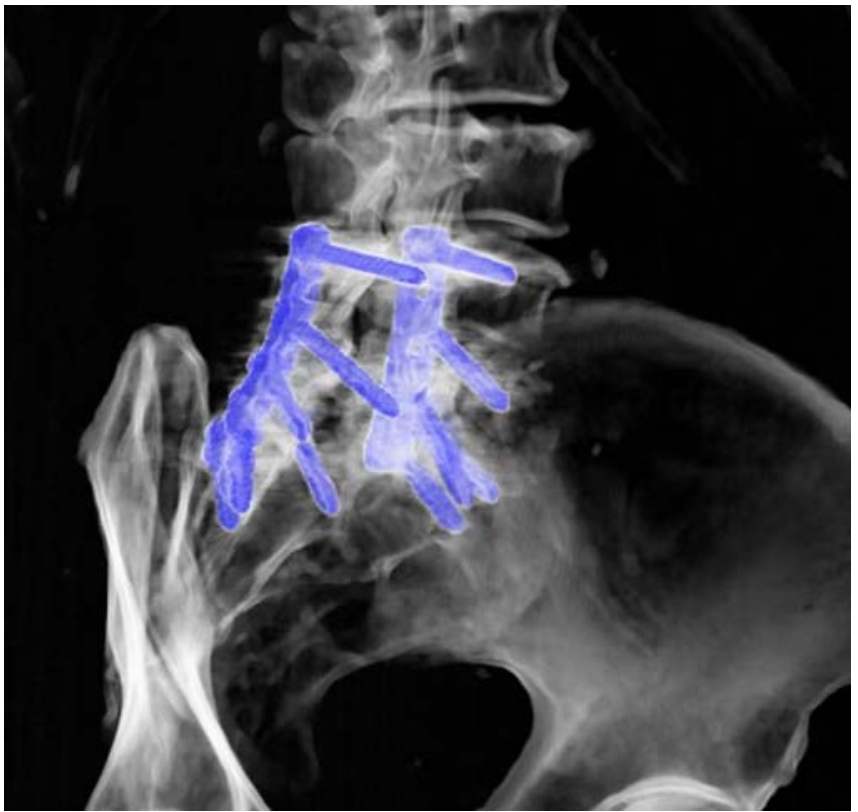

Fig. 5 MSCT, 3D, semi-transluscent reconstruction of the lumbar spine and pelvis. Dense structures of more than 1,000 HU are coloured in blue. Orthopaedic stabilising implants of the spine are clearly visible

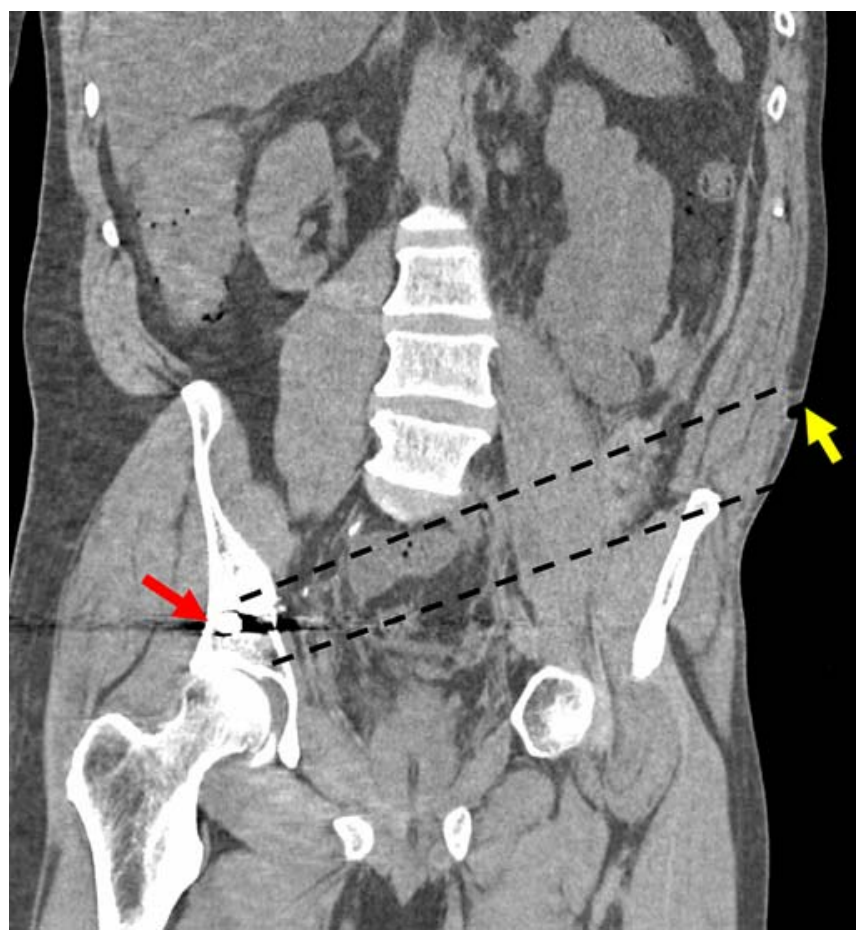

Fig. 6 MSCT, coronal slice of the trunk of a man with a fatal gunshot injury. Note the entrance wound (yellow arrow) at the left side of the abdomen with a wound channel (indicated by dashed lines) leading to the projectile (red arrow) lodged in the right supraacetabular pelvic bone 


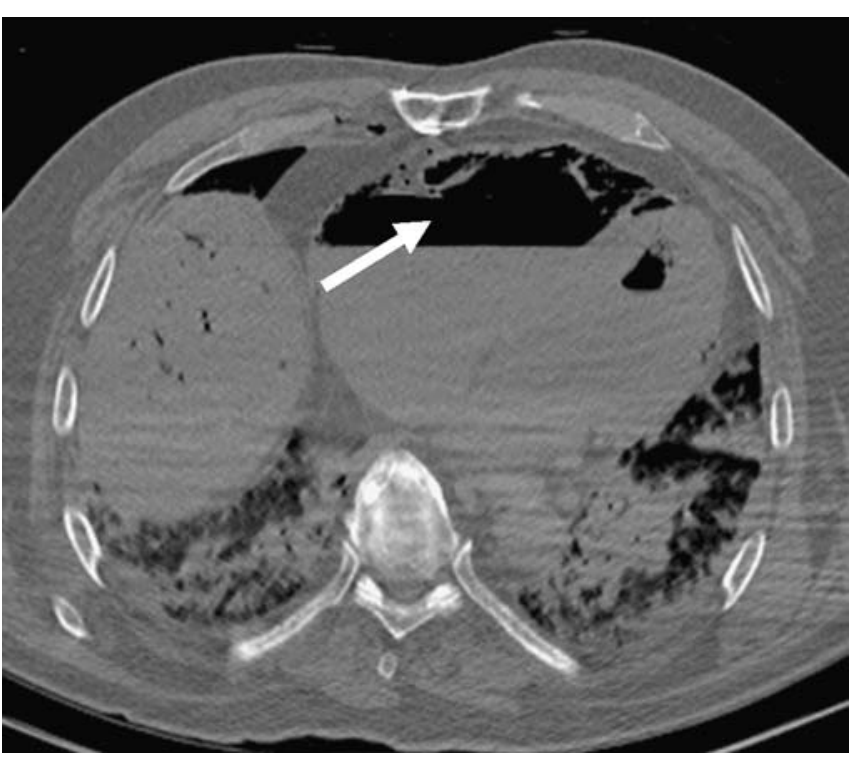

Fig. 7 MSCT, axial slice of the chest of a young woman stabbed to death. A massive accumulation of gas (arrow), in this case air, is seen in the right ventricle, less gas in the left ventricle, the right pleural cavity and the chest wall

\section{Limitations}

Both MSCT and MRI have basic disadvantages: MSCT, while it is rapid and offers excellent spatial resolution for the visualisation of the skeleton, foreign bodies, and gas, has an inferior contrast resolution in the soft tissues and,

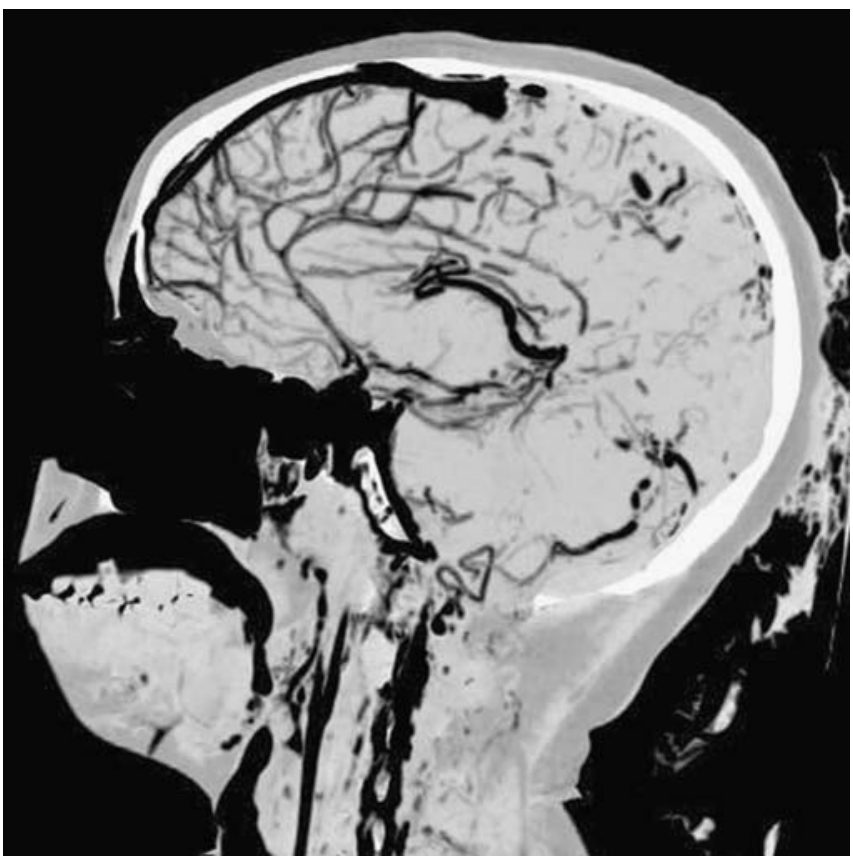

Fig. 8 MSCT, sagittal minimum intensity projection image of the head of the woman seen in Fig. 7. Note the gas-filled blood vessels corresponding to lethal air embolism therefore, is not the method of choice for the depiction of soft-tissue and solid organ lesions.

The opposite is true for MRI: cortical bone and other hard materials, such as forensically important foreign bodies, are seen merely as artefact-producing gaps in the image, whereas soft-tissues and their pathology are shown excellently (Fig. 11). However, as dense metallic objects such as projectiles cause artefacts in both CT and MRI, their immediate neighbourhood may not be reproduced adequately for diagnosis. Despite these minor shortcomings, the generally assumed danger of ferromagnetic foreign bodies is usually not present in MRI of gunshot victims due to the fact that projectiles consist mainly of non-ferromagnetic material, such as lead, and therefore create no problems during MRI.

Furthermore, since our scanner used for corpses does not offer parallel imaging, examination of a body from the head to the pelvis and sometimes the extremities is timeconsuming and may take one to several hours, which is unacceptable in routine forensic practice.

Beyond these limitations inherent to the methods, postmortem imaging introduces difficulties not seen in living subjects. First, even before putrifaction arises, post-mortem changes of many organs, such as the lung, the bowel or the blood, create deviations from normal findings that may be difficult to differentiate from pathologic entities present during life and from those responsible for death. Second and most important, the lack of an ongoing circulation is

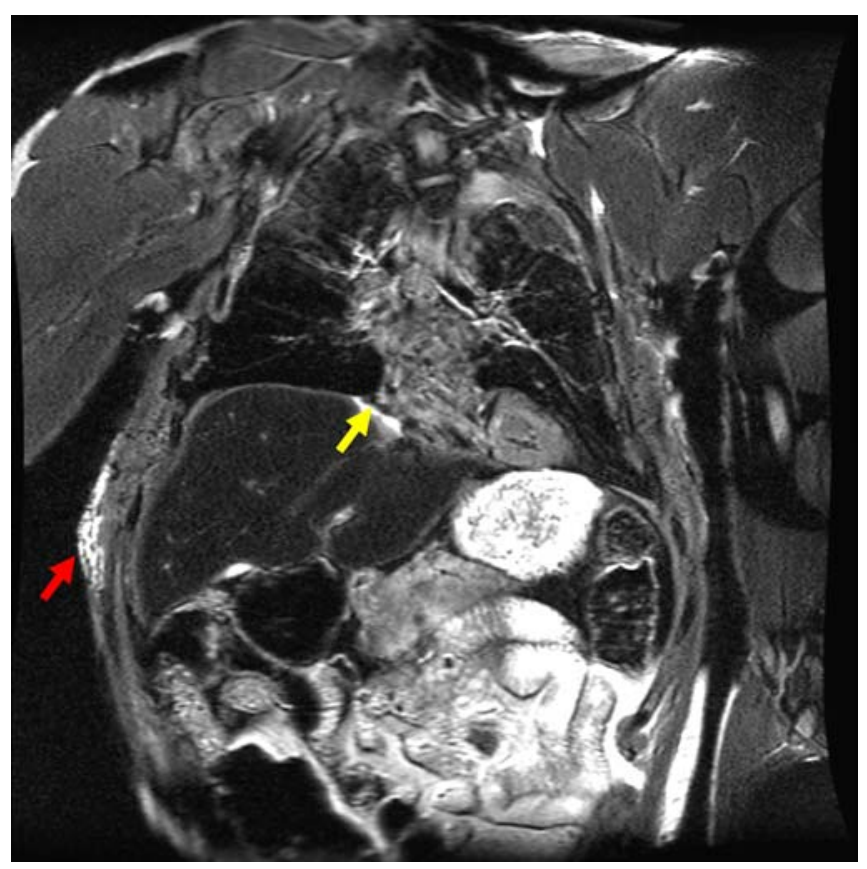

Fig. 9 Coronal T2-weighted SE sequence (TE $98 \mathrm{~ms} / \mathrm{TR}$ 4,000 ms) of the trunk of a traffic accident victim. The signal-intense white region at the upper medial liver surface (yellow arrow) corresponds to a bleeding hepatic laceration. Note the signal-intense region in the right abdominal wall (red arrow) due to a haematoma 

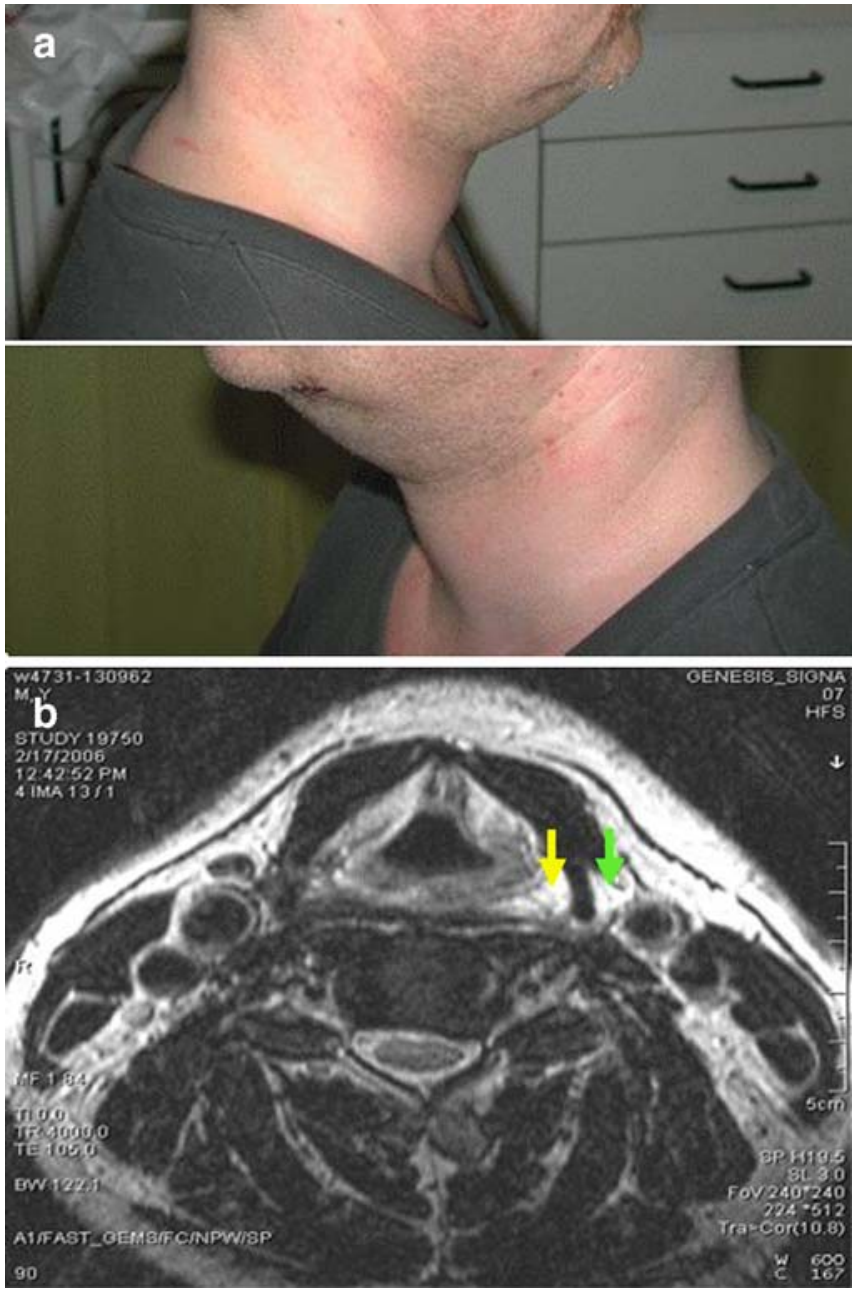

Fig. 10 Photographs of a barman who was assaulted and strangled by a guest (a) and the axial MR image (b). Note the signal-rich area reflecting haemorrhage around the left side of the larynx (yellow arrow). Higher up, the vicinity of haemorrhage and the carotid sinus may point to traumatic dysfunction of the regulation of blood pressure

the reason for the impossibility to use intravenous contrast enhancement of vessels and tissues, a critical supplement to many clinical examinations.

Another major drawback of radiological imaging methods is their incapacity (as to date) to show pathological changes on a microscopic scale.

\section{Outlook}

As MR scan acquisition times of $2-3 \mathrm{~h}$ for the vulnerable body regions (head, neck and trunk) are unacceptable, other solutions for a fast MR examination must be used. A viable approach to this problem is parallel imaging using many integrated coils and acquisition channels to minimise examination time with no quality loss. Evaluation of this technique is currently underway.
To overcome the obstacle of the lack of circulation, postmortem approaches to angiography have recently been implemented. First studies have either used catheter-based contrast injection or established a post-mortem circulation using a modified heart-lung machine. They show amazing results of unexpected quality and allow for a demonstration of the vascular system which is impossible to reach by a traditional autopsy [32-34].

Micro-MR and micro-CT [35-38] have shown promising results in improving spatial resolution down to a submillimetric level. As both methods require a removal of tissue samples, this obviously is no longer non-invasive imaging; nonetheless, this minimally invasive approach is accepted by many of those that reject open autopsy. MSCT-
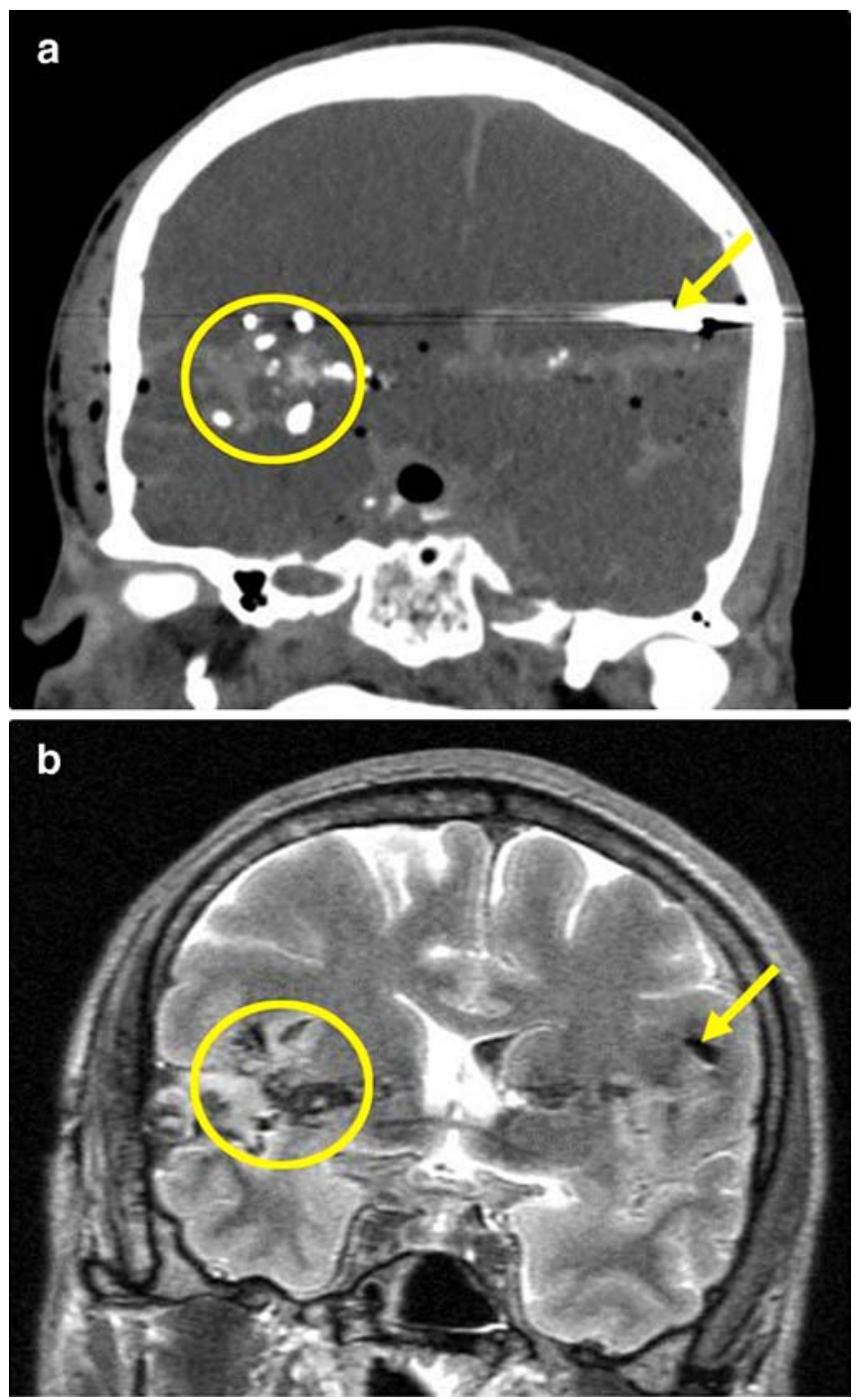

Fig. 11 Coronal reformation of MSCT scan after suicidal gunshot to the right temple (a) and corresponding coronal T1-weighted MRI (b). Note that bone fragments (encircled) are radioopaque (white) at CT but do not contain mobile hydrogen nuclei and produce a poor (dark) MR signal. The projectile located in the left cerebral hemisphere (arrow) shows similar signal characteristics 
guided biopsy, also minimally invasive, might solve a major problem and deliver the histological, microbiological and chemical information needed [39].

Another field of interest in post-mortem imaging is the estimation of the post-mortem interval. Using traditional methods, assessing decomposition of body tissues is an extremely difficult task, as the speed of putrefaction depends on a multitude of circumstances. Forensic entomology has produced promising results. However, this time-consuming method is obviously only applicable in cases of insect infestation. By measuring the relative concentrations of certain amino acids in the brain noninvasively, MR spectroscopy has opened an alternative approach that might become a method of choice [40].

\section{Discussion}

Post-mortem imaging, according to the authors' opinion, is already today an important complement to autopsy, and its role in forensic medicine is constantly growing.

We believe that this minimally invasive approach may prove useful in many ways. First, acceptance of traditional autopsy has decreased dramatically in the past few years. By scanning corpses, a triage is possible. On the other hand, due to the greater acceptance of non-invasive forensic methods, a broader triage system is possible: when signs of a third party involvement exist at postmortem imaging, then the arguments for an autopsy are much stronger. One might hypothesise that screening a greater proportion of deceased persons by imaging might help detect a larger number of homicides. The minimally invasive approach of surface scanning, MSCT and MRI, combined with post-mortem angiography and imageguided biopsy, has also the potential to replace traditional autopsy in many cases, and therefore to provide a viable compromise for post-mortem examinations for cultural circles in which autopsy is not welcome.

Certain caveats do, however, exist; natural causes of death are difficult to determine and the most common cause of sudden and unexpected death - namely, arrhythmogenic coronary artery disease - cannot be diagnosed by postmortem imaging [41, 42]. However, the same is true for the autopsy of such cases; besides coronary stenoses or occlusions, possibly in combination with a cardiac hypertrophy and unspecific findings such as a pulmonary congestion, these cases generally do not show macroscopic signs of a cardiac ischemia. The diagnosis of an arrhythmogenic cardiac arrest is based on pre-existing pathologies, unspecific findings, exclusion of other causes of death and the possible (rare) presence of histological changes of the cardiac musculature. Although autopsy facilitates the sampling of tissue specimens, image-guided biopsies may serve as a minimally invasive alternative to enable histological examinations and aid in diagnosing the cause of death.

However, even if several causes of natural death cannot be diagnosed accurately by post-mortem imaging, this present shortcoming is of secondary importance in a forensic setting where, if a natural death has been diagnosed, the district attorney will usually (with the exception of alleged malpractice, etc.) close the case.

Examination of surviving victims, the other pillar of our project, due to its non-invasive character is on its way to become a standard in forensic medicine. Thus, lesions undetected at external clinical inspection will be available in a graphic, observer-independent fashion, which should fulfil the requirements of a modern court of law.

Another advantage of virtual imaging is its data structure ideal for digital storage: by creating such 3D images of bodies, instruments and vehicles suspected of creating injuries and crime scenes, cases can be re-examined decades later, even after burial of the body and liberation of the crime scene. This re-examination can be undertaken by a completely different, unprejudiced group, giving rise to "forensic telemedicine", a method which would correspond to the routinely performed "telepathology" conferences in clinical pathology. This technique will enhance quality assurance by allowing a neutral second opinion and a benchmark comparison.

In conclusion, the non-invasive or minimally invasive approach envisioned by post-mortem surface scanning and MSCT as well as MRI has several advantages to current forensic examination techniques, namely:

- Precise, objective and clear documentation of forensic findings for the court

- Calibrated, 3D documentation of findings

- Quality assurance through digital data archivation and transfer

- Reduction of psychological trauma for the next-of-kin

- Improved judicature in cultures with low autopsy acceptance.

Acknowledgements The authors would like to thank the Virtopsy Foundation for financial support and extend their gratitude to the staff of the departments of Diagnostic Radiology and Neuroradiology and the Division of Magnetic Resonance Spectroscopy and Methodology of the University of Bern for the excellent collaboration, to R. Dorn and U. Koenigsdorfer for assistance during the autopsies and to R. and W. Bolliger PhD, for help in manuscript preparation. 


\section{References}

1. Lundberg GD (1998) Low-tech autopsies in the era of high-tech medicine: continued value for quality assurance and patient safety. JAMA 280:12731274

2. Wullenweber R, Schneider V, Grumme T (1977) [A computer-tomographical examination of cranial bullet wounds]. Z Rechtsmed 80:227-246

3. Brogdon BG (1998) Forensic radiology, 1st edn. CRC press, Boca Raton

4. Vogel H (1997) Gewalt im Röntgenbild: Befunde bei Krieg, Folter und Verbrechen. Echomed 41:13-42

5. Levy AD, Abbott RM, Mallak CT, Getz JM, Harcke HT, Champion HR, Pearse LA (2006) Virtual autopsy: preliminary experience in high-velocity gunshot wound victims. Radiology 240:522-528

6. Poulsen K, Simonsen J (2006) Computed tomography in connection with medico-legal autopsies. Forensic Sci Int PMID 16891070

7. Ljung P, Winskog C, Persson A, Lundstrom C, Ynnerman A (2006) Full body virtual autopsies using a state-ofthe-art volume rendering pipeline. Trans Vis Comput Graph 12:869-876

8. The Japan Society of Autopsy Imaging home page. Available at: http://plaza. umin.ac.jp/\%7Eai-ai/english.htm. Accessed February 2007

9. Dedouit F, Telmon N, Costagliola R, Otal P, Joffre F, Rouge D (2007) Virtual anthropology and forensic identification: report of one case. Forensic Sci Int 52:960-964

10. Thali MJ, Braun M, Markwalder TH, Brueschwiler W, Zollinger U, Malik NJ, Yen K, Dirnhofer R (2003) Bite mark documentation and analysis: the forensic 3D/CAD supported photogrammetry approach. Forensic Sci Int 135:115-121

11. Thali MJ, Braun M, Wirth J, Vock P, Dirnhofer R (2003) 3D surface and body documentation in forensic medicine: 3-D/CAD photogrammetry merged with 3D radiological scanning. J Forensic Sci 48:1356-1365

12. Thali MJ, Braun M, Buck U, Aghayev E, Jackowski C, Vock P, Sonnenschein M, Dirnhofer R (2005) VIRTOPSY: scientific documentation, reconstruction and animation in forensics: individual and real 3D data based geometric approach including optical body/object surface and radiological CT/MRI scanning. J Forensic Sci 50:428-442
13. Buck U, Naether S, Braun M, Bolliger $\mathrm{S}$, Friederich H, Jackowski C, Aghayev E, Christe A, Vock P, Dirnhofer R, Thali MJ (2007) Application of 3D documentation and geometrical reconstruction methods in traffic accident analysis: with high resolution surface scanning, radiological MSCT/MRI scanning and real data based animation. Forensic Sci Int 170:20-28

14. Thali MJ, Yen K, Schweitzer W, Vock P, Boesch C, Ozdoba C, Schroth G, Ith $\mathrm{M}$, Sonnenschein M, Doernhofer T, Scheurer E, Plattner T, Dirnhofer R (2003) Virtopsy, a new imaging horizon in forensic pathology: virtual autopsy by postmortem multisclice computed tomography (MSCT) and magnetic resonance imaging (MRI) - a feasibility study. J Forensic Sci 48:386-403

15. Dirnhofer R, Jackowski C, Vock P, Potter K, Thali MJ (2006) VIRTOPSY: minimally invasive, imaging-guided virtual autopsy. Radiographics 26:1305-1333

16. Thali MJ, Yen K, Vock P, Ozdoba C, Kneubuehl B, Sonnenschein M, Dirnhofer R (2003) Image-guided virtual autopsy findings of gunshot victims performed with Multi-Slice Computed Tomography (MSCT) and Magnetic Resonance Imaging (MRI), and subsequent correlation between radiology and autopsy findings. Forensic Sci Int 138:8-16

17. Thali MJ, Schwab CM, Tairi K, Dirnhofer R, Vock P (2002) Forensic radiology with cross-section modalities: spiral CT evaluation of a knife wound to the aorta. J Forensic Sci 47:10411045

18. Thali MJ, Markwalder T, Jackowski C, Sonnenschein M, Dirnhofer R (2006) Dental CT imaging as a screening tool for dental profiling: advantages and limitations. J Forensic Sci 51:113-119

19. Jackowski C, Thali MJ, Sonnenschein M, Aghayev E, Yen K, Dirnhofer R, Vock P (2004) Visualization and quantification of air embolism structure by processing postmortem MSCT data. J Forensic Sci 49:1339-1342

20. Yen K, Vock P, Tiefenthaler B, Ranner G, Scheurer E, Thali MJ, Zwygart K, Sonnenschein M, Wiltgen M, Dirnhofer R (2004) Virtopsy: forensic traumatology of the subcutaneous fatty tissue: multislice computed tomography (MSCT) and magnetic resonance imaging (MRI) as diagnostic tools. J Forensic Sci 49:799-806

21. Bisset R (1998) Magnetic resonance imaging may be alternative to necropsy. BMJ 317:1450
22. Bisset R, Thomas NB, Turnbull IW, Lee S (2002) Postmortem examinations using magnetic resonance imaging: four year review of a working service. BMJ 324:1423-1424

23. Brookes JA, Hall-Craggs MA, Sams VR, Lees VR (1996) Non-invasive perinatal necropsy by magnetic resonance imagining. Lancet 348:11391141

24. Hart BL, Dudley MH, Zumwalt RE (1996) Postmortem cranial MRI and autopsy correlation in suspected child abuse. Am J Forensic Med Pathol 17:217-224

25. Woodward PJ, Sohaey R, Harris DP, Jackson GM, Klatt EC, Alexander AL, Kennedy A (1997) Postmortem fetal MR imaging: comparison with findings at autopsy. AJR Am J Roentgenol 168:41-46

26. Ros PR, Li KC, Vo P, Baer H, Staab EV (1990) Preautopsy magnetic resonance imaging: initial experience. Magn Reson Imaging 8:303-308

27. Patriquin L, Kassarjian A, Barish M, Casserley L, O'Brien M, Andry C, Eustace S (2001) Post-mortem wholebody magnetic resonance imaging as an adjunct to autopsy: preliminary clinical experience. J Magn Reson Imaging 13:277-287

28. Jackowski C, Dirnhofer S, Thali MJ, Aghayev E, Dirnhofer R, Sonnenschein M (2005) Postmortem diagnostics using MSCT and MRI of a lethal streptococcus group A infection at infancy: a case report. Forensi Sci Int 151:157-163

29. Jackowski C, Schweitzer W, Thali MJ, Yen K, Aghayev E, Sonnenschein M, Vock P, Dirnhofer R (2005) Virtopsy: Postmortem imaging of the human heart in situ using MSCT and MRI. Forensic Sci Int 149:11-23

30. Aghayev E, Sonnenschein M, Jackowski C, Thali MJ, Buck U, Yen K, Bolliger S, Dirnhofer R, Vock P (2006) Post-mortem radiology of fatal hemorrhage in postmortem radiology: measurements of cross-sectional areas of major blood vessels and volumes of aorta and spleen by MSCT and volumes of heart chambers by MRI. AJR Am J Roentgenol 187:209-215

31. Yen K, Thali M, Aghayev E, Jackowski C, Schweitzer W, Boesch C, Vock P, Dirnhofer R, Sonnenschein M (2005) Strangulation signs: initial correlation of MRI, MSCT and forensic neck findings. J Magn Reson Imaging 22:501-510 
32. Jackowski C, Sonnenschein M, Thali MJ, Aghayev E, von Allmen G, Yen K, Dirnhofer R, Vock P (2005) Virtopsy: Postmortem minimally invasive angiography using cross section techniques-Implementation and preliminary results. J Forensic Sci 50:1157-1186

33. Jackowski C, Bolliger S, Aghayev E, Christe A, Kilchoer T, Aebi B,

Perinat T, Dirnhofer R, Thali MJ (2006) Reduction of postmortem angiographyinduced tiussue edema by using polyethylene glycol as a contrastagent dissolver. J Forensic Sci 51:1134-1137

34. Grabherr S, Djonov V, Friess A, Thali MJ, Ranner G, Vock P, Dirnhofer R (2006) Postmortem angiography after vascular perfusion with diesel oil and a lipophilic contrast agent. AJR Am J Roentgenol 187:515-523
35. Johnson GA, Benveniste H, Black RD, Hedlund LW, Maronpot RR, Smith BR (1993) Histology by magnetic resonance microscopy. Mag Reson Q 9:1-30

36. Thali MJ, Dirnhofer R, Becker R, Oliver W, Potter K (2004) Is 'virtual histology' the next step after 'virtual autopsy'? Magnetic resonance microscopy in forensic medicine. Magn Reson Imaging 22:1131-1138

37. Engelke K, Karolczak M, Lutz A, Seibert U, Schaller S, Kalender W (1999) [Micro CT: technology and application for assessing bone structure]. Radiologe 39:203-212

38. Thali MJ, Taubenreuther U, Karolczak M, Braun M, Brueschwiler W, Kalender WA, Dirnhofer R (2003) Forensic microradiology: microcomputed tomography (Micro-CT) and analysis of patterned injuries inside of bone. J Forensic Sci 48:1336-1342
39. Aghayev E, Thali MJ, Sonnenschein M, Jackowski C, Dirnhofer R, Vock P (2006) Post-mortem tissue sampling using computed tomography guidance. Forensic Sci Int 166:199-203

40. Scheurer E, Ith M, Dietrich D, Kreis R, Husler J, Dirnhofer R, Boesch C (2005) Statistical evaluation of time-dependent metabolite concentrations: estimation of post-mortem intervals based on in situ 1H-MRS of the brain. NMR Biomed 18:163-172

41. Rutty GN (2007) Are autopsies necessary? The role of computed tomography as a possible alternative to invasive autopsies. Rechtsmedizin 17:21-28

42. Roberts IS, Benbow EW, Bisset R, Jenkins JP, Lee SH, Reid H, Jackson A (2003) Accuracy of magnetic resonance imaging in determining cause of sudden death in adults: comparison with conventional autopsy. Histopathology 42:424-430 